\title{
Antineoplastic activity of idazoxan hydrochloride
}

\author{
G. F. Eilon · L. Weisenthal • \\ M. Stupecky · G. Landucci $\cdot$ L. M. Slater
}

Received: 10 November 2008 / Accepted: 3 March 2009 / Published online: 24 March 2009

(C) The Author(s) 2009. This article is published with open access at Springerlink.com

\begin{abstract}
Purpose Idazoxan hydrochloride (IDA) is a 241 molecular weight imidazoline and adrenoreceptor ligand. It binds to mitochondrial membranes and promotes apoptosis of pancreatic beta cells. Since IDA has not been tested against tumor cells, the purpose of our study was to determine if IDA has antineoplastic activity.

Methods We used the conversion of a soluble tetrazolium salt to an insoluble formazan precipitate and differential staining cytotoxicity assays to determine if IDA was cytotoxic to cell lines of murine lung cancer and human prostate cancer, as well as to a variety of fresh human tumor samples. We used flow cytometry to analyze cell death and calreticulin expression.

Results IDA is cytotoxic to both cell lines and against aliquots of specimens of breast, gastric, lung, ovarian and prostate cancers as well as non-Hodgkin's lymphoma. It produces apoptotic cell death and promotes calreticulin expression, suggesting that IDA might be immunomodulatory in vivo.

Conclusion We anticipate that IDA will be clinically useful in cancer treatment.
\end{abstract}

Keywords Idazoxan - Imidazoline receptor .

Calreticulin $\cdot$ Apoptosis $\cdot$ Human tumors

G. F. Eilon

Long Beach, CA, USA

L. Weisenthal

Weisenthal Cancer Group, Huntington Beach, CA 92647, USA

M. Stupecky · G. Landucci · L. M. Slater $(\square)$

Department of Medicine, University of California at Irvine, Irvine, CA 92697-1875, USA

e-mail:1mslater@uci.edu

\section{Introduction}

Imidazoline compounds elicit diverse effects on cell growth and death. At least three subtypes of imidazoline receptors have been described: $I_{1}, I_{2}$ and $I_{3}[1-3]$. These are differentially expressed on a variety of tissues, $\mathrm{I}_{1}$ on brain, kidney, and heart, $\mathrm{I}_{2}$ on brain, kidney, liver, and adipose tissue, and $\mathrm{I}_{3}$ on pancreatic beta cells. Each has putative endogenous ligands and a variety of exogenous ligands which can influence sympathetic control, monoamine turnover, and insulin secretion [4].

In contrast, some imidazoles protect cerebellar granule cells against glutamate-induced toxicity independently of imidazoline receptors [5]. Nutlin, synthesized by Vassielev et al. [6], binds to HDM2 protein inhibiting its interaction with P53 [7]. And other imidazoles inhibit the growth of pancreatic beta cells by unknown mechanisms [8]. These compounds interact with distinct plasma membrane sites termed imidazoline or non-adrenergic imidazoline preferring binding sites [4]. These sites are also concentrated on outer mitochondrial membranes $[9,10]$.

IDA, a benzodioxane-imidazoline analog has high affinity for mitochondrial binding [9]. Examination of the profile of cellular DNA in idazoxan-treated immortalized beta cells revealed that the drug induced an increase in DNA fragmentation within only a few hours of exposure, suggesting the induction of apoptosis [11]. In addition, an increased number of BRIN-BD11 pancreatic beta cells showed positive surface staining with annexin- $\mathrm{V}$ after exposure to IDA for $12 \mathrm{~h}$ (H. Gao and N.G. Morgan, personal communication).

Since studies of apoptosis induction with imidazoles have been performed in pancreatic beta cells, we investigated the potential of IDA to promote apoptotic death in tumor cell lines and fresh human tumor samples. 


\section{Materials and methods}

Tumor cell lines

Lewis lung carcinoma cells (3LL), kindly provided by Dr. V. Pollack (Pfizer, Groton, CT, USA), were stored in liquid nitrogen. They were grown in RPMI-1640 medium supplemented with $10 \%$ fetal bovine serum (FBS), $0.05 \mathrm{mg} / \mathrm{ml}$ gentamicin and $2 \mathrm{mM}$ glutamine (FBS medium at $37^{\circ} \mathrm{C}$ in an atmosphere containing $5 \% \mathrm{CO}_{2}$ and passaged by monolayer culture. The cells were harvested from exponentially growing cultures between passage 5 and 20 .

DU-145 human prostate cancer was obtained from the American Type Culture Collection (ATCC, Rockville, MD, USA). The cells were cultured in DMEM (GIBCO/BRL Life Technologies, Grand Island, NY, USA) supplemented with $10 \%$ defined fetal bovine serum (FBS) (HyClone, Logan, UT, USA) and $0.5 \mu \mathrm{g} / \mathrm{ml}$ gentamicin (Sigma Chemicals, St. Louis, MO, USA). Cells were incubated at $37^{\circ} \mathrm{C}$ in the dark in a humidified atmosphere. All testing was done on cells that were in passage $3-12$.

\section{Reagents}

IDA salt was purchased from Sigma-Aldrich Corp (St. Louis, MO, USA).

\section{Assays}

The MTT assay is based on the conversion of a soluble tetrazolium salt [3-(4.5 dimethylthiazol2-yl)-2.5 diphenyltetrazolium bromide, (MTT)] to an insoluble formazan precipitate by living cells [12]. Cells to be tested were harvested during log phase growth as previously described [13]. After a 48 -h incubation period at $37^{\circ} \mathrm{C}$ in $5 \% \mathrm{CO}_{2}$ $10 \mu \mathrm{l}$ of the drug to be tested was added. Plates were incubated for $24 \mathrm{~h}$ at the above conditions following which MTT $(20 \mu \mathrm{l}, 5 \mathrm{mg} / \mathrm{ml})$ was added to each well. Plates were incubated for $4 \mathrm{~h}$, after which the medium was removed and the resultant formazan crystals solubilized with dimethyl sulfoxide. The optical density (OD) of the solution was then measured at $540 \mathrm{~nm}$ using a multiscan spectrophotometer. The surviving fraction was calculated using the formula: mean of test sample/mean of untreated sample (control).

Apoptotic cells were determined after 24-h exposure to $10 \mu \mathrm{M}$ etoposide or to $10-500 \mu \mathrm{M}$ IDA in standard culture conditions by cytometric staining for propidium iodide and annexin V use of the annexin V-FITC apoptosis Detection Kit (BioVision Research, Mountain View, CA, USA). Calreticulin expression was defined using mouse anti-calreticulin monoclonal antibody (FMC75) Stressgen, (Ann Arbor, MI, USA) and goat anti-mouse
IgG $(\mathrm{H}+\mathrm{L}) \mathrm{Hu}$ ads FITC from Caltag Laboratories (Burlingame, CA, USA).

Cells were analyzed for fluorescence staining using a FACSCalibur (BD Biosciences, San Jose, CA, USA) and CelQuest software. 10,000 cells were gated by forward/side scatter and transferred to a histogram plot. Percent positive staining cells were determined by subtracting isotype control background.

The differential staining cytotoxicity (DiSC) assay was performed as previously described on aliquots of fresh human tumor cells isolated from lymph nodes, effusions, or biopsies. Specimens were most typically submitted via the anatomic pathology laboratories of the submitting hospitals, but were occasionally submitted directly from the operating room. Solid tumor specimens (not exposed to fixatives or frozen) were placed in cold transport medium $\left(\mathrm{CO}_{2}\right.$-independent medium, Invitrogen/GIBCO, Grand Island, NY, USA) supplemented with penicillin/streptomycin, amphotericin B, insulin/selenium/transferring, and $10 \%$ low endotoxin, heat inactivated fetal bovine serum. Specimens were placed in styrofoam shipping boxes, containing $350 \mathrm{~g}$ blocks of "blue ice" frozen to $-20^{\circ} \mathrm{C}$. These were shipped either via FedEx priority overnight delivery service or via local land courier. Fluid specimens were mixed well to suspend cell clusters and then poured into sterile $500 \mathrm{ml}$ polypropylene transport bottles (10-15 units of heparin sulfate added per $\mathrm{ml}$ of fluid submitted). More than half of all specimens were submitted via FedEx and over $90 \%$ were received either the day of biopsy or the day following biopsy. After $96 \mathrm{~h}$ in polypropylene culture tubes with and without IDA (6.7-200 ug/ml) Fast Green dye as well as 30,000 acetaldehyde-fixed duck red blood cells (DRBCs), as internal control, were added. Cells excluding Fast Green were viable and unstained, whereas "dead cells" and DRBCs stained bright green. The slides were counterstained so that viable normal cells and tumor cells could be identified morphologically and quantitated against the DRBCs from which the percent of viable tumor cells were compared between IDA containing and control cultures and expressed as percent of control cell survival $[14,15]$.

Ethical standards

Cell lines and patient materials were handled in accord with institutional guidelines and patient consent requirements. A United States patent has been filed by the University of California, "Idazoxan as an anticancer agent."

\section{Results}

IDA is cytotoxic to both $3 \mathrm{LL}$ and DU-145 cells as displayed in Fig. 1 at concentrations of $0.05-1.0 \mathrm{mg} / \mathrm{ml}$. 


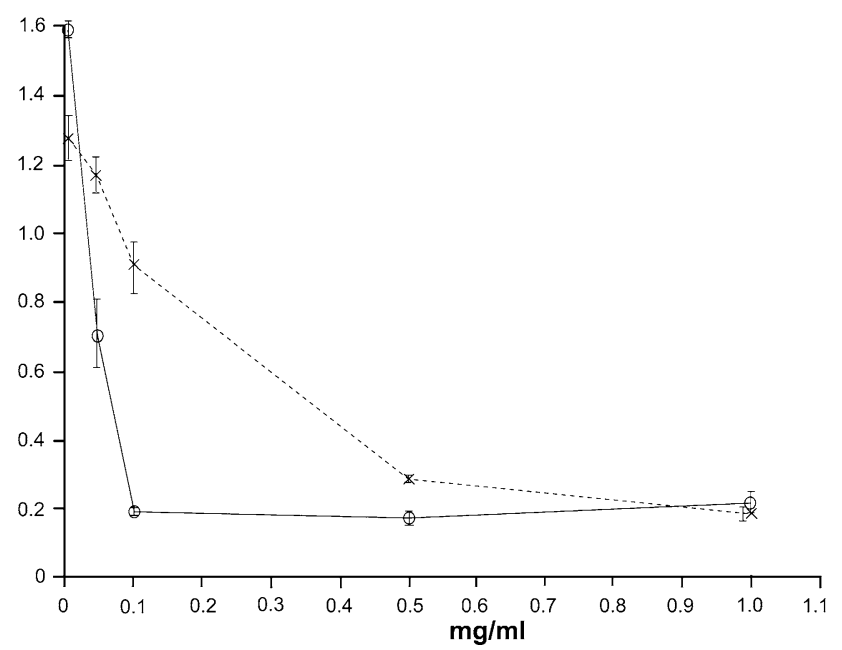

Fig. 1 Cytotoxicity of murine Lewis Lung Cancer (3LL), (solid line) and human prostate cancer (DU-145), (broken line) produced by IDA after 24-h drug exposure in MTT assay

Figure 2 compares the induction of annexin $\mathrm{V}$ expression by IDA and by etoposide, the positive control after 24-h drug exposure resulting in 95.7 versus $93.5 \%$ apoptotic 3LL cells, respectively. Calreticulin expression due to IDA also exceeds that achieved by etoposide in 3LL and DU-145 cells by 90 versus $40 \%$ and 51 versus 3\%, respectively, although at greater IDA concentration (Fig. 3).

Table 1 displays the cytotoxic activity of IDA against 11 different fresh tumor samples derived from patients with a variety of neoplasms (the majority of which had been previously treated with the indicated chemotherapeutics) determined after $96 \mathrm{~h}$ of continuous exposure to $6.7-200 \mathrm{mcg} / \mathrm{ml}$ IDA. The data points are limited by the amount of material available per patient. However, a consistent dose response effect is present, which is most striking in the gastric and breast cancer samples. In five specimens, there were sufficient numbers of readily identifiable normal cells to score drug effects against these normal cells. In one specimen, IDA had no detectable effect on normal mesothelial cells, while reducing the survival of tumor cells (adenocarcinoma of unknown primary) to $60 \%$ of control (tested at the $67 \mu \mathrm{g} /$ $\mathrm{ml}$ concentration). The same concentration $(67 \mu \mathrm{g} / \mathrm{ml})$ reduced the survival of normal lymphocytes $(n=3)$ and normal macrophages $(n=1)$ to $1 \%$ of control.

\section{Discussion}

Our results show that IDA is cytotoxic to cell lines of murine Lewis Lung cancer and human prostate cancer DU-145 in vitro (Fig. 1). The former arose spontaneously in a $\mathrm{C} 57 \mathrm{Bl} / 6$ mouse as an anaplastic lung cancer. It was used for many years in cancer drug development by the
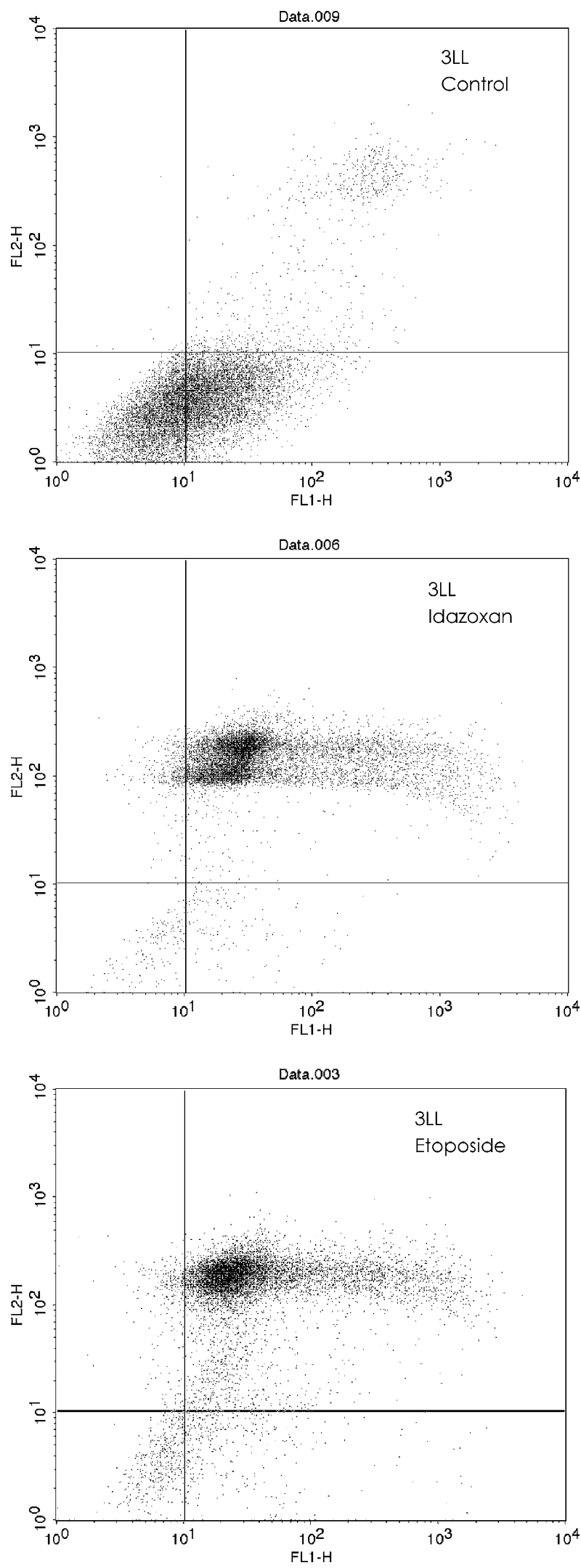

Fig. 2 Apoptosis detection by cytometric staining for Propedium iodide and annexin $\mathrm{V}$ after $24-\mathrm{h}$ exposure to $500 \mu \mathrm{M}$ IDA compared to $10 \mu \mathrm{M}$ etoposide (positive control) 95.7 versus $93.5 \%$ 
Fig. 3 Calreticulin expression of apoptotic cells induced by exposure to $10 \mu \mathrm{M}$ etoposide (positive control broken line) compared to $500 \mu \mathrm{M}$ IDA, (solid line) at $24 \mathrm{~h}$ : $3 \mathrm{LL} 40$ versus 90\%, DU-145 3 versus 51\%
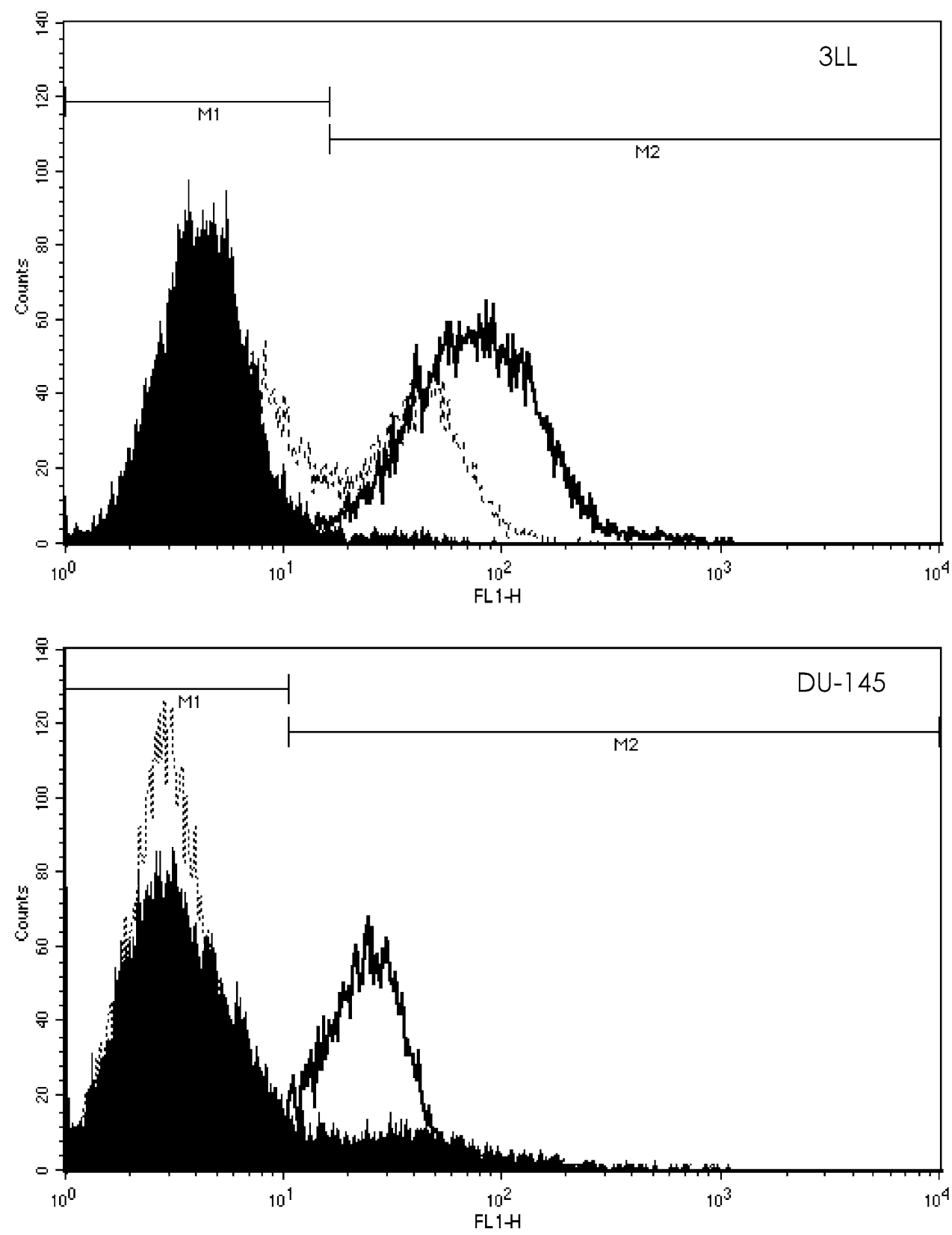

National Cancer Institute, and was found to be the most refractory murine tumor in the screening program for effective chemotherapeutic agents [16, 17].

IDA is also cytotoxic to a variety of fresh human tumor samples in vitro (Table 1). At the highest IDA concentration tested, $200 \mathrm{mcg} / \mathrm{ml}$, only $1 \%$ of the cells of the five tumor specimens tested remained viable, but the deepest dose responses occurred in untreated gastric cancer and previously treated breast and prostate cancer specimens. Previously treated non-Hodgkin's lymphoma, and an ovarian cancer as well as an untreated poorly differentiated tumor of unknown primary site were the most sensitive tumors. Whereas a previously treated ovarian tumor as well as previously treated colon cancer and adenocarcinoma of unknown primary site specimens were relatively resistant.

The ability to predict in vivo responses of patients from in vitro chemosensitivity testing of their tumors has been intensively studied. The DiSC assay is one of a class of fresh tumor, primary culture assays measuring cell death as an endpoint. Other assays of this class include the MTT assay, ATP assay, and fluorescein diacetate assay. The above four assays have been compared with each other and have been found to give similar results in fresh tumor specimens in cases where more than $70 \%$ of the viable cells present are tumor cells [18]. The major advantage of the DiSC assay is that it provides the cell death endpoint which is most specific for drug effects on tumor cells, in a mixed 
Table 1 Idazoxan cytotoxicity against aliquots of fresh human tumor samples by DiSC assay expressed as percent viability compared to control

\begin{tabular}{llrrr}
\hline Tumor & Prior therapy & Idazoxan concentration (mcg/ml) \\
\cline { 3 - 4 } & & 6.7 & 20 & 67 \\
\hline Adenocarcinoma unknown primary & gem, oxa; cis, cap & & 100 & 60 \\
Breast & cyt, dox; pac & 70 & 1 \\
Colon & cap, oxa & 74 & 52 \\
Gastric & None & 75 & 2 & 1 \\
NHL (diffuse mixed large/small cell) & fl, rit & 100 & 23 & 1 \\
NHL (mantle cell) & cyt, dox, onc, pred, rit; bor, gem, cyt & 91 & 35 & 1 \\
Non-small cell lung & gem, cis; fu, leu & & 1 \\
Ovarian & car, pac; bev & & 1 \\
Ovarian & car, pac; gem, dxl & 80 & 30 & 1 \\
Poorly differentiated unknown primary & None & & 28 & 3 \\
Prostate & doc & 85 & 80 & 2 \\
\hline
\end{tabular}

bev bevacizumab; bor bortezomib; cap capecitabine; car carboplatin; cis cisplatin; cyt cyclophosphamide; doc docetaxel; dox doxorubicin; dxl doxil; $f$ fludarabine; fu 5 -fluorouracil; gem gemcitabine; leu leukovorin; onc vincristine; oxa oxaliplatin; pac paclitaxel; prd prednisone; rit rituximab

population of tumor and normal cells. Cell death endpoints have been consistently found to predict for both patient response to chemotherapy and for patient survival with chemotherapy, in 40 published studies in more than 2,000 patients [19]. Therefore, the DiSC assay results reported in Table 1 suggest that IDA will prove to be an effective clinical chemotherapeutic agent.

There is a considerable clinical experience with the use of IDA. During the 1980s and 1990s IDA was studied in patients with a variety of neuropsychiatric disorders, including Alzheimer's dementia, bipolar depression, schizophrenia, supranuclear palsy, and Parkinson's disease [20-24]. IDA dosing could be tolerated at $240 \mathrm{mg}$ daily with minimal side effects of nausea and asymptomatic decline in standing diastolic blood pressure [21]. No pancreatic toxicities were described in the use of IDA in neuropsychiatric patients. However, since the maximum tolerated dose of IDA has not been defined, a Phase I trial would be required before specific trials of drug efficacy could be carried out in patients with malignancies.

Many effective chemotherapeutic drugs produce tumor apoptosis [25]. Flow cytometric analysis using annexin V expression shows that $96 \%$ of $3 \mathrm{LL}$ cells become apoptotic after 24-h exposure to IDA. Recent studies have shown that some, but not all, apoptotic promoting chemotherapeutic drugs enhance membrane expression of calreticulin, the cytoplasmic chaperone protein. Since it is appreciated that calreticulin expressing apoptotic tumor cells are frequently immunogenic and are recognized by the host immune system leading to tumor rejection $[26,27]$, we defined calreticulin expression by $3 \mathrm{LL}$ and DU-145 cells after exposure to IDA. Ninety percent of 3LL cells and $40 \%$ of DU-145 cells overexpress calreticulin after $24-\mathrm{h}$ incubation with IDA from baselines of less than 3 and $9 \%$, respectively.
Since chemotherapeutic agents kill tumors by first-order kinetics, it has been suggested that tumor cure depends on the host immune response to eradicate residual viable tumor [28-30]. Recent observation regarding chemotherapeutically induced calreticulin overexpression by apoptotic tumor cells support this concept [26, 27]. The ability of IDA to produce calreticulin overexpression in $3 \mathrm{LL}$ and DU-145 suggest that it might promote immune recognition and rejection of syngeneic tumors by an intact host.

Etoposide is an immunosuppressive topoisomerase II inhibiting drug that is widely used clinically to treat a variety of tumors, including leukemia, lymphoma, lung, and testicular cancer [31]. It impairs the integrity of DNA strand replication, promotes apoptosis and is used as a positive control for calreticulin expression induction [25, 32]. We have previously shown that etoposide produces important immune activating effects in vivo leading to rejection of murine models of leukemia and lung cancer [33, 34]. Mice bearing L1210 acute lymphatic leukemia which had achieved a sustained response to etoposide rejected a subsequent L1210 challenge [33]. This effect is tumor specific and mediated by CD8-T lymphocytes [35]. We have also shown that mice bearing $3 \mathrm{LL}$ effectively treated with etoposide behave similarly. In addition, the majority of naïve mice that had survived an inoculation of viable $3 \mathrm{LL}$ cell, which had previously been incubated in vitro with etoposide rejected challenge with wild type 3LL [34].

Although the biochemical mechanism by which IDA promotes tumor cell death is not known, our work shows that IDA has antineoplastic activity in vitro and its cytotoxic effect is produced apoptotically. This effect is associated with a marked induction of calreticulin membrane expression, suggesting that in addition to its potential development as a cytotoxic antineoplastic agent, IDA may 
also prove useful in initiating host immunologic responses against autologous tumors. In vivo studies exploring these possibilities are underway. Our preliminary results in this area are encouraging since we have observed a 50\% reduction in the growth of $3 \mathrm{LL}$ tumor in mice treated with IDA, and delay in the growth of wild type 3LL cells in syngeneic host mice previously inoculated with calreticulin expressing $3 \mathrm{LL}$ cells conditioned in vitro with IDA.

Acknowledgments This work was supported by the Margaret and Walter Schmid Family Endowment, The Jacob Wallerstein Foundation, and the Marcia Slater Society for Research in Leukemia. We wish to thank Harry Wallerstein, MD for his continuous encouragement and Noah Wagner for his secretarial assistance.

\section{Conflict of interest statement None.}

Open Access This article is distributed under the terms of the Creative Commons Attribution Noncommercial License which permits any noncommercial use, distribution, and reproduction in any medium, provided the original author(s) and source are credited.

\section{References}

1. Greney H, Ronde P, Magnier C et al (2000) Coupling of I(1) imidazoline receptors to the cAMP pathway: studies with a highly selective ligand, benazoline. Mol Pharmacol 57:1142-1151

2. Regunathan S, Youngson C, Raasch W et al (1996) Imidazoline receptors and agmatine in blood vessels: a novel system inhibiting vascular smooth muscle proliferation. J Pharmacol Exp Ther 276:1272-1282

3. Morgan NG, Chan SL (2001) Imidazoline binding sites in the endocrine pancreas: can they fulfill their potential as targets for the development of new insulin secretagogues? Curr Pharm Des 7:1413-1431

4. Regunathan S, Reis DJ (1996) Imidazoline receptors and their endogenous ligands. Annu Rev Pharmacol Toxicol 36:511-544

5. Olmos G, DeGregorio-Rocasolano N, Paz R et al (1999) Protection by imidazol(ine) drugs and agmatine of glutamate-induced neurotoxicity in cultured cerebellar granule cells through blockade of NMDA receptor. Br J Pharmacol 127:1317-1326

6. Vassilev LT, Vu BT, Graves B et al (2004) In vivo activation of the p53 pathway by small-molecule antagonists of MDM2. Science 303:844-848

7. Wade M, Wong ET, Tang M et al (2006) Hdmx modulates the outcome of p53 activation in human tumor cells. J Biol Chem 281:33036-33044

8. Mourtada M, Elliott J, Smith SA et al (2000) Effects of imidazoline binding site ligands on the growth and viability of clonal pancreatic beta-cells. Naunyn Schmiedebergs Arch Pharmacol 361:146-154

9. Limon I, Coupry I, Lanier SM et al (1992) Purification and characterization of mitochondrial imidazoline-guanidinium receptive site from rabbit kidney. J Biol Chem 267:21645-21649

10. Tesson F, Prip-Buus C, Lemoine A et al (1991) Subcellular distribution of imidazoline-guanidinium-receptive sites in human and rabbit liver. Major localization to the mitochondrial membrane. J Biol Chem 266:155-160

11. Gao H, Mourtada M, Morgan NG (2003) Effects of the imidazoline binding site ligands idazoxan and efaroxan on the viability of insulin secreting BRIN-BD 11 cells. J Pancreas 4:117-124
12. Carmichael J, DeGraff WG, Gazdar AF et al (1987) Evaluation of a tetrazolium-based semiautomated colorimetric assay: assessment of chemosensitivity testing. Cancer Res 47:936-942

13. Cho J, Lee Y, Lutzky J et al (1995) Collateral sensitivity to radiation and CIS-platinum in a multidrug-resistant human leukemia cell line. Cancer Chemother Pharmacol 37:168-172

14. Weisenthal LM, Marsden JA, Dill PL et al (1983) A novel dye exclusion method for testing in vitro chemosensitivity of human tumors. Cancer Res 43:749-757

15. Wilbur DW, Camacho ES, Hilliard DA et al (1992) Chemotherapy of non-small cell lung carcinoma guided by an in vitro drug resistance assay measuring total tumour cell kill. Br J Cancer $65: 27-32$

16. Browder T, Butterfield CE, Kraling BM et al (2000) Antiangiogenic scheduling of chemotherapy improves efficacy against experimental drug-resistant cancer. Cancer Res 60:1878-1886

17. Goldin A, Venditti JM, Macdonald JS et al (1981) Current results of the screening program at the Division of Cancer Treatment, National Cancer Institute. Eur J Cancer 17:129-142

18. Weisenthal LM, Nygren P (2008) Current status of cell culture drug resistance testing. http://weisenthal.org/oncol_t.htm

19. Weisenthal LM (2008) Functional profiling with cell culture assays for targeted drug therapy. American Society of Clinical Oncology Gastrointestinal Cancer Symposium, 2007. http://www.asco.org/ ASCO/Abstracts+\%26+Virtual+Meeting/Abstracts?\&vmview= abst_detail_view\&confID=45\&abstractID=10630 (click on "slides" below abstract)

20. Goodwin GM, Conway SC, Peyro-Saint-Paul H et al (1997) Executive function and uptake of $99 \mathrm{mTc}$-exametazime shown by single photon emission tomography after oral idazoxan in probable Alzheimer-type dementia. Psychopharmacology 131:371378

21. Grossman F, Potter WZ, Brown EA et al (1999) A double-blind study comparing idazoxan and bupropion in bipolar depressed patients. J Affect Disord 56:237-243

22. Litman RE, Su TP, Potter WZ et al (1996) Idazoxan and response to typical neuroleptics in treatment-resistant schizophrenia. Comparison with the atypical neuroleptic, clozapine. Br J Psychiatry 168:571-579

23. Ghika J, Tennis M, Hoffman E et al (1991) Idazoxan treatment in progressive supranuclear palsy. Neurology 41:986-991

24. Rascol O, Arnulf I, Peyro-Saint Paul H et al (2001) Idazoxan, an alpha-2 antagonist, and L-DOPA-induced dyskinesias in patients with Parkinson's disease. Mov Disord 16:708-713

25. Kaufmann SH (1989) Induction of endonucleolytic DNA cleavage in human acute myelogenous leukemia cells by etoposide, Camptothecin, and other cytotoxic anticancer drugs: a cautionary note. Cancer Res 49:5870-5878

26. Obeid M, Tesniere A, Ghiringhelli F et al (2007) Calreticulin exposure dictates the immunogenicity of cancer cell death. Nat Med 13:54-61

27. Clarke C, Smyth MJ (2007) Calreticulin exposure increases cancer immunogenicity. Nat Biotechnol 25:192-193

28. Frei E (1972) Combination cancer therapy: presidential address. Cancer Res 32:2593-2607

29. Schipper H, Goh CR, Wang TL (1995) Shifting the cancer paradigm: must we kill to cure? J Clin Oncol 13:801-807

30. Skipper HE (1965) The effects of chemotherapy on the kinetics of leukemic cell behavior. Cancer Res 25:1544-1550

31. Aisner J, Lee JE (1991) Etoposide current and future status. Cancer 67:215-219

32. Lee W-C, Lin K-Y, Chen C-M et al (1991) Induction of heatschock response and alterations of protein phosphorylation by a novel topoisomerase II inhibitor, with angulatin A, in 9L rat brain tumor cells. J Cell Physiol 149:66-76 
33. Slater LM, Stupecky M, Sweet P et al (2002) Enhancement of leukemia rejection by mice successfully treated for L1210 leukemia due to low dose compared to high dose VP-16. Leuk Res 26:203-206

34. Slater LM, Stupecky M, Sweet P et al (2001) Etoposide induction of tumor immunity in Lewis lung cancer. Cancer Chemother Pharmacol 48:327-332
35. Slater LM, Sweet P, Stupecky M et al (1995) Cyclosporin A/VP16 produced immunity to L1210 leukemia: the participation of cytotoxic CD8 T-lymphocytes. Clin Immunol Immunopathol 75:239-245 